\title{
Camphor intoxication treated by charcoal haemoperfusion
}

\author{
BRIAN H. MASCIE-TAYLOR* \\ L.R.C.P., M.R.C.S.
}

\author{
BRIAN WIDDOP $\dagger$ \\ B.Sc., Ph.D.
}

\author{
AleXANDER M. Davison* \\ B.Sc., M.D., F.R.C.P. \\ *Department of Renal Medicine, St James's University Hospital, Leeds LS9 7TF, and \\ $\dagger$ Poisons Unit, New Cross Hospital, London SE14 5ER
}

\begin{abstract}
Summary
A case of camphor intoxication in which lipid haemodialysis and charcoal haemoperfusion were applied is described. Although the patient recovered rapidly with no resultant sequelae, the analytical data indicated that extra-corporeal therapy was ineffective.
\end{abstract}

\section{Introduction}

Camphor is used as a proprietary preparation, most often as a $20 \%$ solution in arachis oil, and is applied to the skin for the supposed relief of muscle pain and symptoms of the common cold. Intoxication is usually accidental and, although reports are rare, Silbert (1973) drew attention to the risk of camphor poisoning in children. Symptoms following ingestion include tremors, hallucinations, major fits and renal damage. Death can follow sustained convulsions and central paralysis. The minimum lethal dose is thought to be approximately $50 \mathrm{mg} / \mathrm{kg}$, i.e. $15 \mathrm{ml}$ of the $20 \%$ solution in a $60 \mathrm{~kg}$ adult (Gosselin et al., 1976).

Immediate therapy for camphor poisoning includes emesis or gastric lavage, catharsis and the treatment of convulsions with diazepam (Vale and Goulding, 1979). Camphor is highly lipid-soluble and previous workers have suggested lipid haemodialysis as an efficient means of increasing its elimination (Ginn, Anderson and Mercier, 1968). Haemoperfusion using an Amberlite resin column has also been described (Kopelman et al., 1979). A case is now reported of accidental ingestion of a potentially lethal dose of camphor in which charcoal haemoperfusion was used.

\section{Case report}

A 60-year-old woman weighing $50 \mathrm{~kg}$ accidentally swallowed part of the contents of a $100 \mathrm{ml}$ bottle of camphorated oil. The bottle had previously been full and after the incident approximately $75 \mathrm{ml}$ remained, suggesting that a dose of about $5 \mathrm{~g}$ or $100 \mathrm{mg} / \mathrm{kg}$ had been taken. Shortly after ingestion the patient became nauseated and vomited once. She then had a grand mal fit, which was described by her relatives, and a second fit occurred during transport to hospital. The second fit was witnessed by trained medical personnel. On admission to hospital approximately one hour after ingestion of the camphor the patient was responsive only to painful stimuli. There were no other focal neurological signs. Her cardio-vascular and respiratory parameters remained stable and satisfactory. Gastric lavage was carried out with the patient intubated. Since a potentially lethal dose of camphor had been taken an arterio-venous shunt was inserted and she was treated with combined charcoal haemoperfusion and lipid dialysis arranged in series (Haemocol., Smith and Nephew Pharmaceuticals Ltd: EX 29, Extra-corporeal: Intralipid 10\%, KabiVitrum). This therapy was started approximately $3 \mathrm{hr}$ postingestion. After one hour of treatment, slight haemolysis was noted in the blood leaving the lipid dialysis kidney and this was therefore removed from the circuit. Blood for plasma camphor assay was obtained at the points illustrated (Fig. 1). Plasma camphor concentrations were measured by a specific gas-chromatographic technique and the results are shown in Table 1.

The treatment was continued for $4 \mathrm{hr}$ by which time the patient had returned completely to normal with no neurological abnormalities. Liver function tests, urea and electrolytes remained normal throughout. The patient was discharged 4 days after admission, and at follow-up one month later was well and free of any neurological sequelae.

\section{Discussion}

This patient had accidentally ingested a potentially lethal dose of camphor and within $30 \mathrm{~min}$ showed 
evidence of CNS toxicity. Her plasma camphor concentration $(3.1 \mathrm{mg} / \mathrm{l})$ at the start of perfusion therapy was far greater than that of $1.7 \mathrm{mg} / \mathrm{l}$ measured in the seriously poisoned patient described

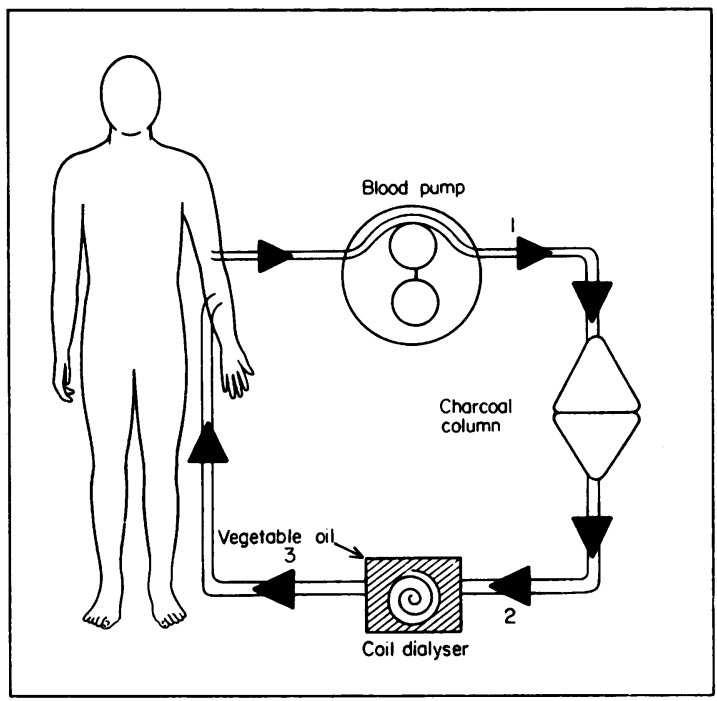

FIG. 1. Schematic diagram of dialysis system. Blood samples for analysis obtained at points 1,2 and 3 .

TABle 1. Plasma camphor concentrations (mg/l) during treatment with extra-corporeal system

\begin{tabular}{lccc}
\hline Time & $(1)$ & $(2)$ & (3) \\
\hline 1830 & 3.1 & $<0.05$ & $<0.05$ \\
1900 & 2.2 & $<0.05$ & $<0.05$ \\
1940 & 1.3 & $<0.05$ & \\
2000 & 1.2 & $<0.05$ & \\
2030 & 1.1 & $<0.05$ & \\
2130 & $<0.05$ & $<0.05$ & \\
\hline
\end{tabular}

N.B. (a) The first sample (1830) was taken immediately after starting haemoperfusion. (b) Flow rate $240 \mathrm{ml} / \mathrm{min}$. (c) $0.05 \mathrm{mg} / \mathrm{l}$ is the minimum concentration detectable by the analytical method used.

by Kopelman et al. (1979). The clearance of camphor by the charcoal column approximated to that of the blood flow rate $(240 \mathrm{ml} / \mathrm{min})$. The clearance of camphor by lipid haemodialysis could not be investigated in this case because of the high clearance of the charcoal column with consequently no camphor entering the lipid system. Lipid haemodialysis with the method used unfortunately caused ${ }^{\complement}$. haemolysis, presumably as a result of water passing $\overrightarrow{\bar{c}}$ across the dialysis membrane from the isotonic fat emulsion.

The amount of camphor removed from the circulation by charcoal haemoperfusion was cal- $\overrightarrow{\mathbb{D}}$ culated by the formula devised by Winchester et al. (1975):

Amount removed,

$$
\frac{1}{2} \times(t y-t x) \times\left[\left(C_{1}-C_{2}\right)+\left(C_{3}-C_{4}\right)\right] \times F,
$$

where $C_{1}$ and $C_{2}$ are the plasma camphor concentrations in the column inlet and outlet blood ato time $t x, \mathrm{C}_{3}$ and $\mathrm{C}_{4}$ are the corresponding values at time $t y ; F$ is the blood flow-rate through the column.:Applying this formula to the plasma camphor.concentration data gives a value of only $48.7 \mathrm{mg}$ for? the total amount of camphor removed, i.e. less than $1 \%$ of the ingested dose. On this basis it is difficult to accept that haemoperfusion was beneficial.

\section{Conclusion}

Camphor is extensively sequestrated in the extravascular tissues and the amount present in the blood represents a very small proportion of theo total body load. Although in this case charcogil haemoperfusion cleared the blood of camplar $\overrightarrow{0}$ efficiently, the fraction of the ingested dose retrievesd. was minuscule. It is concluded that extra-corpore procedures such as lipid haemodialysis or haemoperfusion are of no benefit in serious cases of camphor poisoning.

\section{References}

Ginn, H.E., Anderson, K.E. \& Mercier, R.K. (1968)ㅡㅡㅁ Camphor intoxication treated by lipid dialysis. Journal of 3 the American Medical Association, 203, 230.

Gosselin, R.E., Hodge, H.C., Smith, R.P. \& Gleason, M.N. (1976) Journal of the American Medical Press, Clinical Toxicology of Commercial Products, 4th edn, p. 77. Williams \& Wilkins Co., Baltimore.

Kopelman, R., Miller, S., Kelly, R. \& Sunshine, I.O (1979) Camphor intoxication treated by resin hemoperfusion. Journal of the American Medical Association, 241, 727.

SILBERT, J.R. (1973) Poisoning in children. British Medical Journal, 1, 803.

VAle, J.A. \& Goulding, R. (1979) A Concise Guide to the Management of Poisoning, p. 13. Dista Products Ltd, Basingstoke U.K.

Winchester, J.F., EdWARds, R.O., TILsTONE, W.J. \&N Woodcock, B.G. (1975) Activated charcoal hemoper-fusion and experimental acetaminophen poisoning. $N$ Toxicology and Applied Pharmacology, 31, 120. 